\title{
Effect of Key Parameters on Jacalin Extraction from Aqueous Phase into Anionic Reverse Micelles
}

\author{
Sharifah Fathiyah Sy Mohamad ${ }^{1{ }^{*}}$, Farhan Mohd Said ${ }^{1}$, Mimi Sakinah Abdul Munaim², and Shahril \\ Mohamad $^{1}$
}

${ }^{1}$ Faculty of Chemical and Natural Resources Engineering, Universiti Malaysia Pahang,

Lebuhraya Tun Razak, 26300 Gambang, Pahang, Malaysia

${ }^{2}$ Faculty of Technology, Universiti Malaysia Pahang, Lebuhraya Tun Razak, 26300 Gambang, Pahang, Malaysia

\begin{abstract}
${ }^{*}$ Corresponding author:
email:fathiyah@ump.edu.my

Received: October 16, 2018

Accepted: October 30, 2018

DOI: $10.22146 / \mathrm{ijc} .39705$

Abstract: This study demonstrates the extraction of jacalin from the crude extract of jackfruit seeds using anionic surfactant based reverse micellar system, sodium bis(2ethylhexyl) sulfosuccinate (AOT) in isooctane. Effects of various parameters, such as, $\mathrm{NaCl}$ concentration (0.05-1 M), pH of aqueous phase ( $\mathrm{pH} 4-10$ ), AOT concentration (5$150 \mathrm{mM}$ ), contact time (5-30 $\mathrm{min})$ and phase volume ratio (0.5-5) on the transfer efficiency of jacalin was evaluated by changing one factor at a time (OFAT) while keeping the other parameters constant. A maximum of $83 \%$ of protein transfer was achieved after an equal volume of organic and aqueous phase was stirred for 20 min using $20 \mathrm{mM}$ AOT at $\mathrm{pH} 5$ aqueous phase containing $0.1 \mathrm{M} \mathrm{NaCl}$. The findings demonstrated AOT reverse micellar system as a promising and effective method to extract and purify jacalin from the crude protein mixture.
\end{abstract}

Keywords: reverse micelles; sodium bis(2-ethylhexyl) sulfosuccinate (AOT); jacalin; forward extraction efficiency (FEE)

\section{- INTRODUCTION}

Jacalin is the major plant lectins contained in the seeds of jackfruit (Artocarpus heterophyllus) belonging to the Moraceae family. Chatterje et al. were the first to identify jacalin, which constitutes more than half of the readily available proteins in the crude extract of jackfruit seeds [1-2]. Since then, jacalin has been extensively studied due to its many exciting biological activities [3-4]. Furthermore, jacalin possess a unique ability to specifically recognize tumor-associated, Thomsen-Friedenreich (TF) antigens which have antiproliferative effects on human breast cancer and non-small lung cancer cells. This remarkable ability has made jacalin as a suitable protein molecule to carry nanoparticles conjugated with anticancer biomolecules and to selectively deliver these conjugates to tumor cells [5-6].

The traditional approaches to extract and purify jacalin from its crude extract usually involved several procedures, including salts or organic solvents precipitation, followed by chromatographic techniques such as affinity chromatography, ion-exchange, and size exclusion [7]. Previously, jacalin has been purified by affinity chromatography on immobilized IgA or IgA1, as well as on cross-linked guar gum matrix, due to the reactivity of jacalin towards galactomannan [8]. The affinity chromatography of jacalin on cross-linked guar gum is proved to be a much simpler method and has been widely adopted due to its reliability, precision in selectivity and accuracy [9-10]. However, this method can be too expensive, tedious, time-consuming, produce low recovery yield and not suitable for continuous applications [7]. Thus, there is a need for a new purification approach with similar precision as in chromatography but with lower cost and ease of scalingup.

Reverse micellar extraction (RME) has been recognized as an attractive alternative for downstream processing of biomolecules due to its simplicity, low 
surface tension at the interface and ease of scaling up [11]. Reverse micelles are optically transparent, self-assembled aggregates of surfactant clustered around water droplets suspended in an organic solvent [12]. The micelles are capable of solubilizing biomolecules of interest in its inner aqueous core according to their hydrophobicity, size, and charge without excessive loss of activities [13]. The biomolecules are protected from denaturation by the surfactant molecules, which shielded the solubilized biomolecules from the organic medium [14]. Over the years, numerous applications of RME have been demonstrated for the purpose of separating and purifying several proteins, enzymes, and antibiotics [15-16]. Several researchers have also demonstrated successful attempts in lectins extraction and purification using sodium bis(2ethylhexyl) sulfosuccinate (AOT) in isooctane reverse micelle system without losing their functional properties [17-18].

RME is a two-step process consists of a forward extraction, which solubilizes target biomolecule contained in the aqueous phase to the reverse micellar solution and a backward extraction, which strips off the biomolecule from reverse micelles by adding a new aqueous solution. The efficiency of forward extraction depends on several factors such as the concentration of surfactant, aqueous phase $\mathrm{pH}$, salt concentration and many more. To the best of our knowledge, although the use of AOT in isooctane reverse micelle system for biomolecule extraction and purification is well established, no comprehensive work was dedicated on the recovery of jacalin from the jackfruit seeds using the AOT reverse micelles. Moreover, the ability of AOT reverse micelles to selectively transfer the jacalin from a crude extract is heavily influenced by the complex interaction of several factors during forward extraction. Hence, a more systematic and detail report on the effect of these parameters on the uptake of jacalin into the reverse micellar phase is needed.

The current study aims to explore the possibility of using an anionic reverse micellar system of AOT/isooctane to isolate jacalin from the crude extract of jackfruit seeds. Investigations on the extraction behavior of the forward extraction of jacalin into anionic reverse micelles were assessed by manipulating the aqueous phase $\mathrm{pH}$, salt concentration, AOT concentration, phase volume ratio and contact time. The reported outcome could demonstrate the suitability of extracting jacalin from crude protein mixture using AOT reverse micelles, hence justifying subsequent step of recovering jacalin from the reverse micelles using a new stripping aqueous solution.

\section{- EXPERIMENTAL SECTION}

\section{Materials}

\section{Plant materials}

Whole jackfruits (Artocarpus heterophyllus Lam.) variety, locally known as Mastura were purchased from a local market in Kuantan, Pahang, Malaysia.

\section{Chemicals}

Sodium bis(2-ethylhexyl) sulfosuccinate of $96 \%$ purity (AOT), sodium chloride $(\mathrm{NaCl})$, sodium hydroxide $(\mathrm{NaOH})$ and bovine serum albumin (BSA) were procured from Sigma-Aldrich. The organic solvent, isooctane, and hydrochloric $(\mathrm{HCl})$ acid were purchased from Merck. The anionic surfactant (AOT) was used as received. All solutions were prepared using Milli-Q-purified water (Millipore System, Bedford, MA).

\section{Instrumentation}

This work used $\mathrm{pH}$ meter (Mettler-Toledo), magnetic stirrer (Daihan), glassware, centrifuge (Eppendorf 5810R) and UV spectrophotometer (Hitachi) for forward extraction process.

\section{Procedure}

\section{Preparation of jackfruit seed powder}

The method of preparing jackfruit seeds powder were adopted from Tulyathan et al. [19] with slight modifications. The seeds were manually separated from flesh, soaked in water overnight and cleaned with running tap water to remove the outer layers (white arils) and other contaminants. The thin spermoderm layers (brown coat) covering the whitish-cotyledons were also removed by rubbing the seeds between the hands. The seeds were then cut into thin slices and dried 


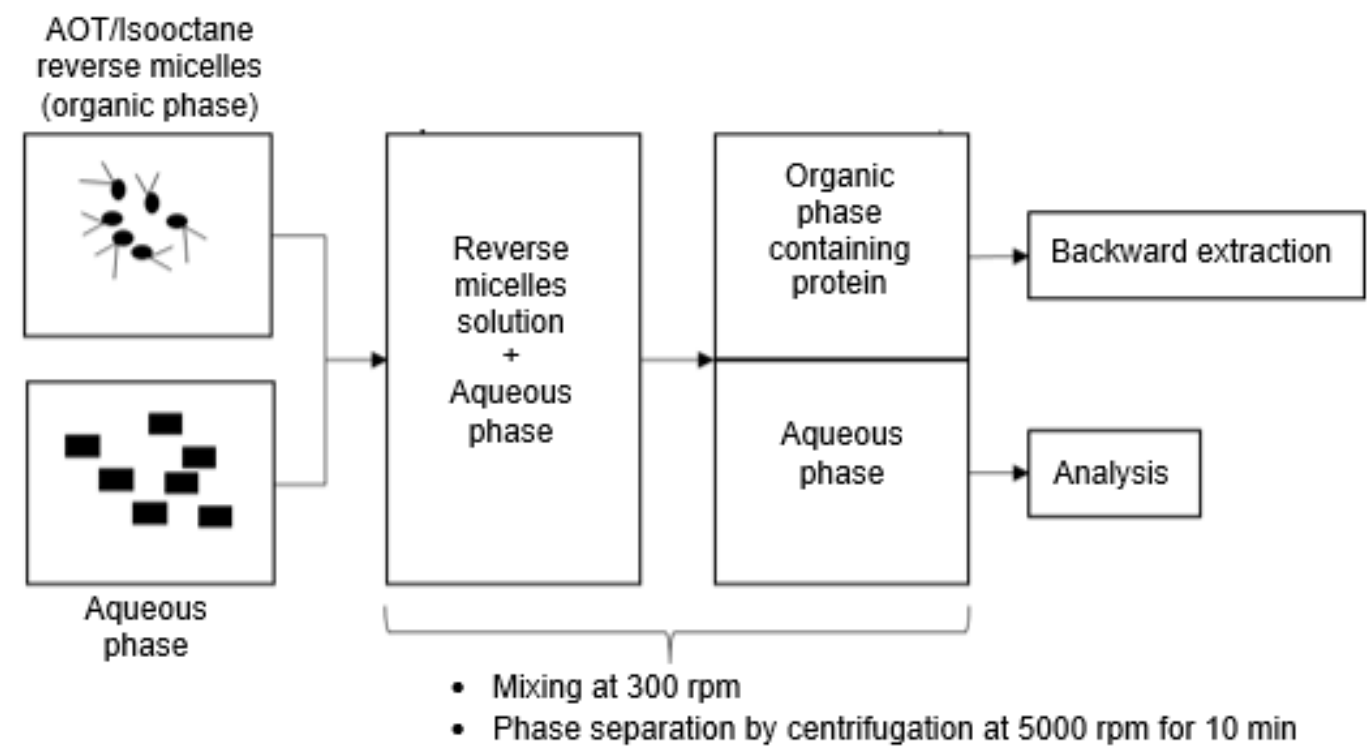

Fig 1. Experimental setup for forward extraction of jacalin from the aqueous phase into AOT reverse micelles

at $37{ }^{\circ} \mathrm{C}$ for $24 \mathrm{~h}$ in an oven (Heraeus). The dried seeds were ground into a powder by a mixer-grinder, passed through an 80 -mesh sieve to remove big chunks, packed in plastic pouches and stored at refrigerator (below $10^{\circ} \mathrm{C}$ ) until used.

\section{Crude extract preparation for reverse micellar extraction}

The crude extract containing jacalin were prepared following the procedure described by Zuraidah [20]. Fine jackfruit seeds powder was soaked at a 1:10 ratio $(\mathrm{w} / \mathrm{v})$ in $10 \mathrm{mM}$ phosphate-buffered-saline (PBS), pH 7.4 at $4{ }^{\circ} \mathrm{C}$ for $6 \mathrm{~h}$. The mixture was incubated at $25^{\circ} \mathrm{C}$ with constant shaking at $150 \mathrm{rpm}$ in a water bath (Memmert) for $5 \mathrm{~h}$ and then centrifuged for $20 \mathrm{~min}$ at $10000 \mathrm{rpm}$ (Eppendorf $5810 \mathrm{R})$. The supernatant obtained was filtered through a $0.45 \mu \mathrm{m}$ syringe filter and kept at $4{ }^{\circ} \mathrm{C}$ for further uses in the next step as crude extract.

\section{Formation of reverse micellar system}

The organic phase was made up of various AOT concentrations $(10-200 \mathrm{mM})$ by dissolving AOT in isooctane. The aqueous phase was comprised of dilutions of crude extract samples in various concentrations of $\mathrm{NaCl}$ solution at different $\mathrm{pHs}$. The $\mathrm{pH}$ of the aqueous phase was adjusted to appropriate value through the addition of acid $(0.10 \mathrm{M} \mathrm{HCl})$ or alkali $(0.10 \mathrm{M} \mathrm{NaOH})$.

\section{Forward extraction with anionic AOT surfactant}

Forward extraction was performed using the phase transfer method as illustrated in Fig. 1. Equal volumes of aqueous and organic phases were slowly contacted in a $50 \mathrm{~mL}$ centrifuge tubes and magnetically stirred at $300 \mathrm{rpm}$ for a series of time at room temperature. The resulting mixture was centrifuged at $5000 \mathrm{rpm}$ for $10 \mathrm{~min}$ (Eppendorf 5810R) to achieve a distinct phase separation between the organic phase loaded with jacalin and the aqueous phase. The solution collected from the lower layer after forward extraction were analyzed against appropriate blank experiments consisted of an aqueous phase with no protein. Influence of different parameters were evaluated using one factor at a time (OFAT) experiments at different concentrations of AOT (5-150 mM), ionic strengths of the aqueous solution (0.05-1 M), aqueous phase $\mathrm{pH}(4-10)$, volume ratio of organic phase to aqueous phase (0.5-5) and contact time (5-30 min). In all experiments, the initial concentration of jacalin in the aqueous phase was fixed at $5.36 \mathrm{mg} / \mathrm{mL}$

\section{Analysis of jacalin concentration}

The samples of feed, aqueous phase and organic phase after forward extraction were analyzed for jacalin concentration using Lowry assay with bovine serum albumin (BSA) as a standard [4]. The transfer of protein 
into reverse micellar phase $(\% \mathrm{R})$ were then calculated according to the following Eq. 1 [21]:

$\mathrm{R}(\%)=\frac{\mathrm{C}_{\text {org }} \mathrm{V}_{\text {org }}}{\mathrm{C}_{0} \mathrm{~V}_{0}} \times 100$

where $\mathrm{C}_{\text {org }}$ and $\mathrm{V}_{\text {org }}$ signifies the concentration of protein and volume in organic phase after forward extraction, while $\mathrm{C}_{0}$ and $\mathrm{V}_{0}$ represents the concentration of protein and volume in the aqueous phase before forward extraction was carried out.

\section{Gel electrophoresis}

The presence of jacalin in the extracted samples was detected by sodium dodecyl sulfate-polyacrylamide gel electrophoresis (SDS-PAGE) using pre-cast polyacrylamide NuPAGE 4-12\% Bis-Tris gels (1.0 mm thick, 10-wells) (Invitrogen). Aliquots of crude extract, jacalin extracted by reverse micelles and jacalin standard (Sigma-Aldrich) $(20 \mu \mathrm{L})$ were loaded onto the gel wells after $15 \mathrm{~min}$ of heating at $95^{\circ} \mathrm{C}$. The gel was placed in an electrophoresis chamber (Invitrogen) and the electrophoresis was performed at constant $200 \mathrm{~V}$ in running buffer (NuPAGE MES SDS Buffer, Invitrogen) until the dye reached the bottom of the gel. A pre-stained protein ladder was used as a molecular weight reference. The gel was washed in water and stained using PageBlue staining solution (Invitrogen). Destaining was performed overnight at room temperature under slow shaking with an orbital shaker.

\section{- RESULTS AND DISCUSSION}

\section{Effect of Salt Concentration}

The influence of salt concentration on the forward extraction efficiency of jacalin was evaluated by varying the concentration of $\mathrm{NaCl}$ from $0.05 \mathrm{M}$ to $1.0 \mathrm{M}$, while keeping the aqueous phase $\mathrm{pH}$ and $\mathrm{AOT}$ concentration at a constant value of $\mathrm{pH} 5$ and $20 \mathrm{mM}$, respectively. The ionic strength is known as one of the major factors to be considered in the solubilization of proteins in reverse micelles [22]. Ionic strength for the forward extraction is usually provided through the addition of $\mathrm{NaCl}$ or $\mathrm{KCl}$ in the aqueous phase. In this study, $\mathrm{NaCl}$ was preferred over $\mathrm{KCl}$ because the sodium salts are regarded as water structure-forming salt [23]. According to Kinugasa et al. [24], the addition of water structure forming a salt such as

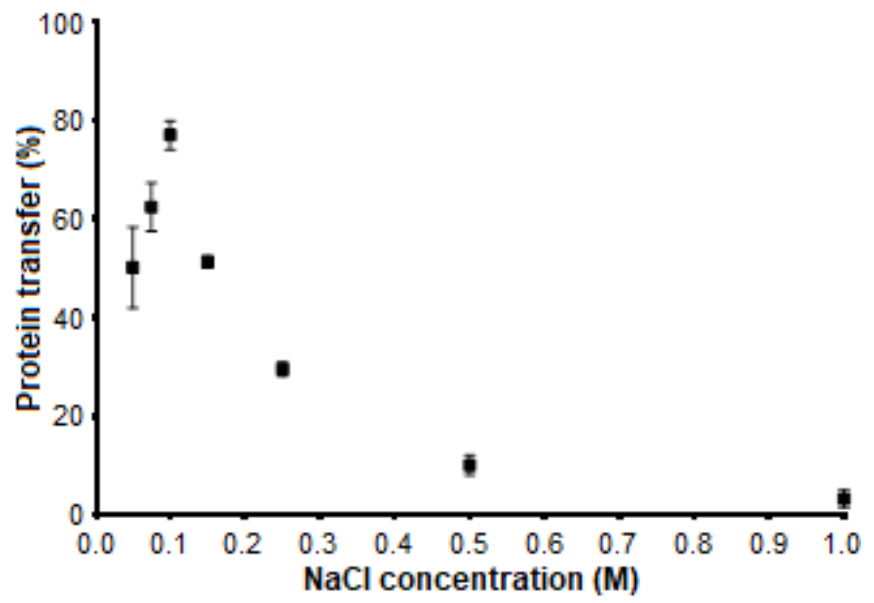

Fig 2. Effect of $\mathrm{NaCl}$ concentration on protein recovery during forward extraction. Experiment conditions: $\mathrm{pH}=$ 5; AOT concentration $=20 \mathrm{mM}$, volume of organic to aqueous phase $=1: 1$, contact time $=20 \mathrm{~min}$

$\mathrm{NaCl}$ is favorable during forward extraction because it could enhance the stability of reverse micelles formed and cause lesser screening of solutes, resulting in higher solubilization of proteins.

As depicted in Fig. 2, various salt concentrations show different influence on jacalin forward extraction efficiency. In the beginning, the transfer of jacalin was increased with the increasing of $\mathrm{NaCl}$ concentration from $0.05 \mathrm{M}$ to $0.10 \mathrm{M}$, due to the salting-in effect. At lower $\mathrm{NaCl}$ concentration, the interaction between the positive-charged sodium ion with the negative-charged surfactants head interrupts the electrostatic forces of protein molecules binding, thus improves the jacalin solubilization into the inner core of the reverse micelles [25]. In the presence of $0.10 \mathrm{M} \mathrm{NaCl}$, the maximum protein transfer of $78 \%$, which indicates that there is a minimum amount of salt needed for a maximum transfer of jacalin into the micellar phase. In the preliminary experiment, when the salt concentration was lower than $0.075 \mathrm{M}$, cloudy aggregates were observed between the micellar and organic phases, most probably because of the strong interaction between proteins and surfactant at low ionic strength. Hence, to form stable reverse micelles, the $\mathrm{NaCl}$ concentration of $0.10 \mathrm{M}$ might be just enough for promoting the interaction between jacalin and surfactant head resulting in the higher protein being transferred. 
However, further increases in the $\mathrm{NaCl}$ concentration from $0.10 \mathrm{M}$ to $1.0 \mathrm{M}$ resulted in a drastic decrease in protein transfer. This trend could be possibly explained by the ability of higher salt concentration in the aqueous phase to decrease the Debye length of the micelles, known as size exclusion effect [11]. Higher salt concentration causes the formation of smaller reverse micelles, which in turns exclude the transfer of larger size biomolecules into the organic phase and resulted in lower forward extraction efficiency. These results were consistent with those reported by other researchers who observed that low ionic strength promoted higher solubilization of biomolecules into the reverse micelles [21]. Meanwhile, the high content of salt present in the aqueous phase might hinder the solubilization of proteins due to the Debye screening effects on their electrostatic interaction [15].

\section{Effect of Aqueous Phase pH}

The $\mathrm{pH}$ of the aqueous phase plays a crucial part in the solubilization of jacalin into reverse micelles by controlling the electrostatic interactions between charged molecules and polar head of surfactant as well as the aggregation properties of surfactant. In this study, various aqueous phase $\mathrm{pH}$ in the range of $\mathrm{pH} 4-10$ were studied, while other parameters such as AOT and $\mathrm{NaCl}$ concentration were kept constant at $20 \mathrm{mM}$ and $0.1 \mathrm{M}$, respectively. Fig. 3 clearly indicates that the aqueous phase $\mathrm{pH}$ strongly affects the quantity of jacalin that can be solubilized in the reverse micellar phase. The protein transfer started to increase at $\mathrm{pH} 4$, until reached maximum (78\%) at $\mathrm{pH}$ 5. It is also worth noting that when the initial aqueous phase $\mathrm{pH}$ is lower than $\mathrm{pH} 4$, the formation of white precipitates was spotted at the interface between the reverse micellar phase and the aqueous phase, suggesting that some protein molecules were denatured by the action of surfactant [26]. However, further increase of the aqueous phase $\mathrm{pH}$ resulted in a reduced number of white flocs formed at the interphase.

In general, selective transfer of target proteins into micellar phase occurs only when the net charge of protein, as determined by the $\mathrm{pH}$ of the aqueous phase, is opposite to that of the surfactant head groups [22]. AOT is an anionic

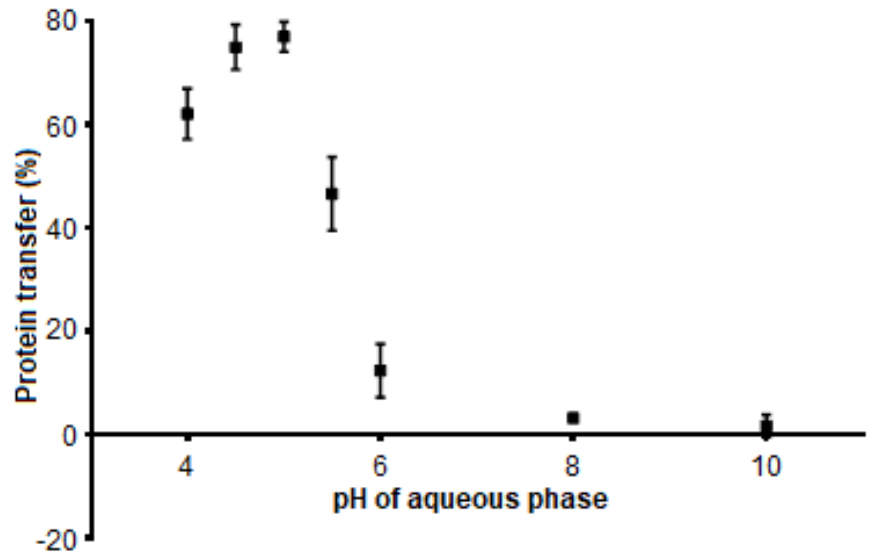

Fig 3. Effect of aqueous phase $\mathrm{pH}$ on protein recovery during forward extraction. Experiment conditions: $\mathrm{NaCl}$ concentration $=0.1 \mathrm{M}$; AOT concentration $=20 \mathrm{mM}$, volume of organic to aqueous phase $=1: 1$, contact time $=15 \mathrm{~min}$

surfactant and can make the interface of reverse micelles negatively charged. The isoelectric point (pI) of jacalin is reported in the range of 7.4-8.3 [27], thus, solubilization of jacalin in reverse micelles is preferred at $\mathrm{pH}$ values below the pI. In the present study, when the $\mathrm{pH}$ of the aqueous phase was below than its isoelectric point, the positively charged jacalin was attracted to the anionic AOT head. Hence, the maximum forward extraction efficiency obtained around $\mathrm{pH} 5$ suggested that not only the $\mathrm{pH} 5$ was more selective, but also that the surface charge density could be the major driving force responsible in facilitating the forward transfer of jacalin. The solubilization of proteins into the reverse micelles might be also affected by the size of the protein molecule. In AOT reverse micelles, small size proteins can be simply transferred at a $\mathrm{pH}$ nearer to its isoelectric point, meanwhile transfer of large size proteins are a little bit tough, thus affecting the forward extraction efficiency [28]. Jacalin is a $66 \mathrm{kDa}$ medium size protein, therefore, a higher $\mathrm{pH}$-pI value is needed for an effective transfer to AOT reverse micelles. Similar studies dealt with AOT reverse micelles have also reported higher recovery of biomolecules at low $\mathrm{pH}$, indicating that $\mathrm{pH}$ value below isoelectric is preferred for forward extraction [29-30].

Interestingly, when the initial $\mathrm{pH}$ of the aqueous phase was around the jacalin's $\mathrm{pI}$ ( $\mathrm{pH} 6$ to $\mathrm{pH}$ 8), the protein transfer was only around $3-12 \%$. Further 
increase of the aqueous phase $\mathrm{pH}$ until $\mathrm{pH} 10$, which was higher than the $\mathrm{pI}$ of jacalin in the crude extract, resulting in the lower transfer of protein. This result suggested that the natural system is largely dominated by the strong electrostatic interactions between the ionic surfactant head groups and the charged proteins.

\section{Effect of AOT Concentration}

Surfactants are important amphiphilic molecules in the formulation of reverse micelles [31]. In the current study, the anionic surfactant, AOT was chosen not only because it was the commonly used in many studies related to protein solubilization in reverse micelles, but mainly due to its ability to form reverse micelles without the addition of another co-surfactant and capability of encapsulating large amounts of water [22]. Forward extractions were carried out at various AOT concentrations in the range of $5 \mathrm{mM}$ to $150 \mathrm{mM}$, which is above the critical micellar composition of AOT/isooctane system $(1 \mathrm{mM})$, while the aqueous phase $\mathrm{pH}$ and $\mathrm{NaCl}$ concentration were fixed at $\mathrm{pH} 5$ and $0.1 \mathrm{M}$, respectively. Fig. 4 demonstrates the effect of different surfactant concentration on the forward extraction efficiency of jacalin. It is apparent that increasing surfactant concentration steadily improved the forward extraction efficiency until a maximum protein transfer $(78 \%)$ was reached at $20 \mathrm{mM}$, indicating the minimum amount of AOT needed for efficient transfer of jacalin into the micellar phase. Further increase of AOT concentration beyond this value resulted in a decrease of protein transfer and finally leveling off at 40 to $80 \mathrm{mM}$. The observed result is in line with another study which also describes an increment in the forward extraction efficiency with increasing surfactant concentration followed by a decrease in the extraction efficiency during forward extraction of miraculin from the crude extract of Synsepalum dulcificum using AOT reverse micelles [30].

The increase of AOT concentration might be responsible for the increase of jacalin transfer from $5 \mathrm{mM}$ to $20 \mathrm{mM}$, due to an increase in the aggregation number of AOT as well as the reverse micelles size [32]. This finding confirms that the protein transfer is subjected to the concentration of surfactant and the size of the micelle

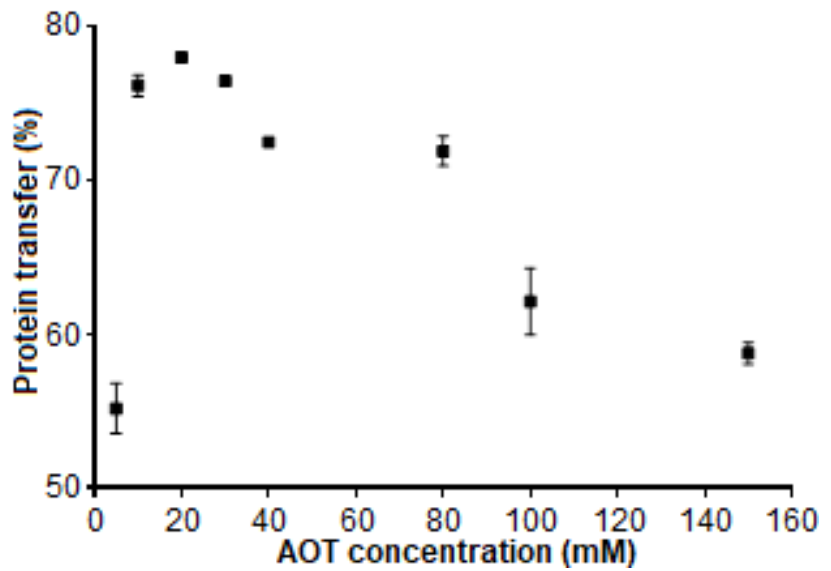

Fig 4. Effect of AOT concentration on protein recovery during forward extraction. Experiment conditions: $\mathrm{NaCl}$ concentration $=0.1 \mathrm{M} ; \mathrm{pH}=5$, volume of organic to aqueous phase $=1: 1$, contact time $=15 \mathrm{~min}$

relative to that protein. At low AOT concentration, the number of reverse micelles increased along with the increasing concentration and more water pools are available to enhance the amount of jacalin solubilized inside the reversed micellar phase, which favored the protein extraction and in turn lead to higher efficiency during forward extraction process [33]. Nevertheless, the solubilization of jacalin into micellar phase was observed to decrease drastically when AOT concentration was further increased from $80 \mathrm{mM}$ to $150 \mathrm{mM}$. Although the formation of reverse micelles also increases with increasing AOT concentration, it could not promote the jacalin to solubilize into the inner water pools of reverse micelles. It was previously reported that higher surfactant concentrations might promote frequent inter-micellar collision between the micelles, resulting in disruption of reverse micellar structure due to the disassembling/deformation of reverse micelle leading to a reduced yield of protein in forward extraction [34].

\section{Effect of Phase Volume Ratio}

The volume ratio between organic to aqueous phase is one of the dominant factors affecting the forward extraction process of proteins. Generally, this ratio should be kept low in forward extraction and high in backward extraction steps for achieving high enrichment of the target protein. As shown here in Fig. 5, increasing 


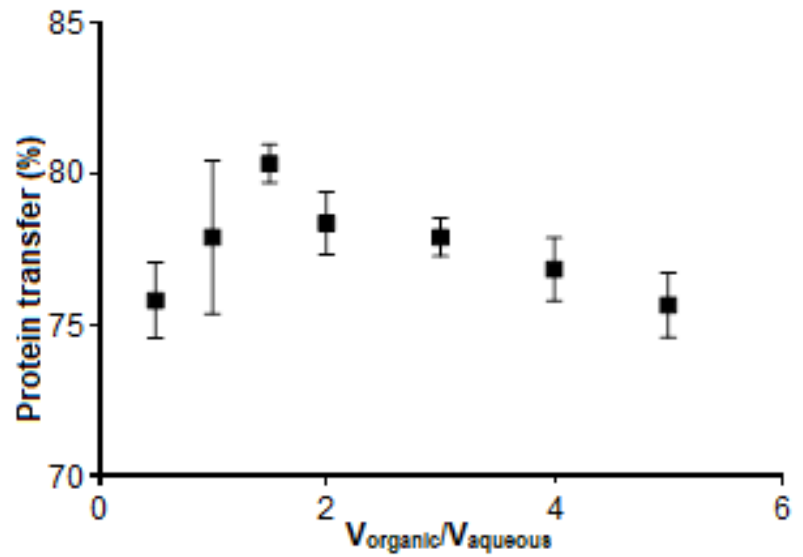

Fig 5. Effect of volume ratio of organic phase to aqueous phase during forward extraction. Experiment conditions: $\mathrm{NaCl}$ concentration $=0.1 \mathrm{M} ; \mathrm{pH}=5$, AOT concentration $=20 \mathrm{mM}$, contact time $=15 \mathrm{~min}$

the phase volume ratio $\left(\mathrm{V}_{\text {org }} / \mathrm{V}_{\text {aq }}\right)$ from $0.5: 1.0$ to 1.5:1.0 also increases the transfer of jacalin into the reverse micellar phase due to the increasing number of the reverse micelles available in the reverse micellar system. However, further increase of the $\mathrm{V}_{\text {org }} / \mathrm{V}_{\text {aq }}$ ratio resulted in a decrease in protein transfer. This result is in line with the observations reported by other researchers which found the efficiency of extraction was decrease with larger volume ratio of organic to aqueous phase beyond 1:1, caused by the change of AOT concentration in the total mixture [35].

\section{Effect of Contact Time}

The time-course experimental transfer of jacalin into the reverse micellar phase is studied by contacting equal volume of organic to aqueous phase at $\mathrm{pH} 5,0.1 \mathrm{M}$ $\mathrm{NaCl}$ and $20 \mathrm{mM}$ AOT. From Fig. 6, it was obvious that the transfer of jacalin into the reverse micellar phase is quite rapid as about $70 \%$ of the protein is transferred within the first $5 \mathrm{~min}$. Maximum transfer of protein (83\%) is reached after $20 \mathrm{~min}$, indicating that equilibrium is reached, and no noticeable changes were observed beyond this value due to the exhaustion of adsorption sites.

\section{Analysis of SDS-Page Profile}

SDS-PAGE electrophoresis was carried out under non-reducing conditions to estimate the molecular weight of the jacalin extracted by reverse micelles, crude

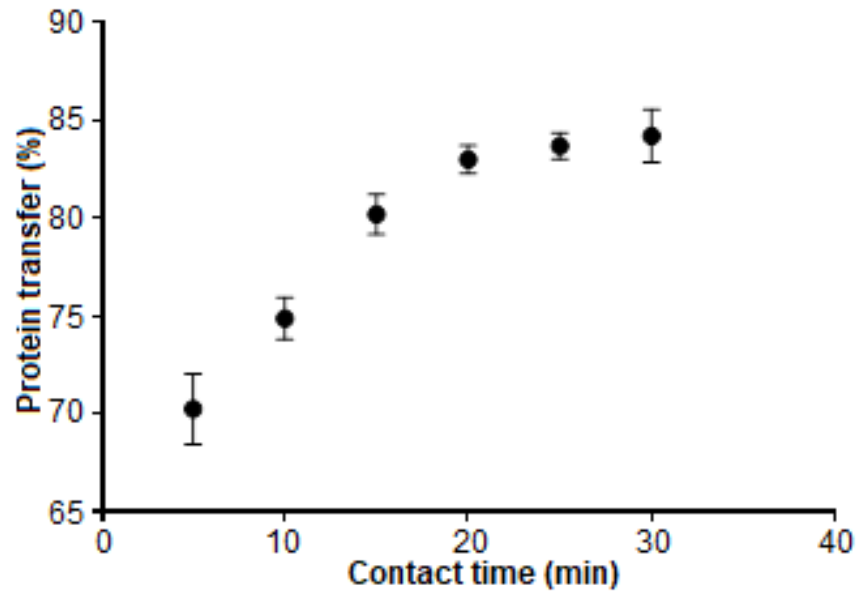

Fig 6. Effect of contact time during forward extraction. Experiment conditions: $\mathrm{NaCl}$ concentration $=0.1 \mathrm{M} ; \mathrm{pH}$ $=5$, AOT concentration $=20 \mathrm{mM}, \mathrm{V}_{\text {org }} / \mathrm{V}_{\text {aq }}=1: 1$

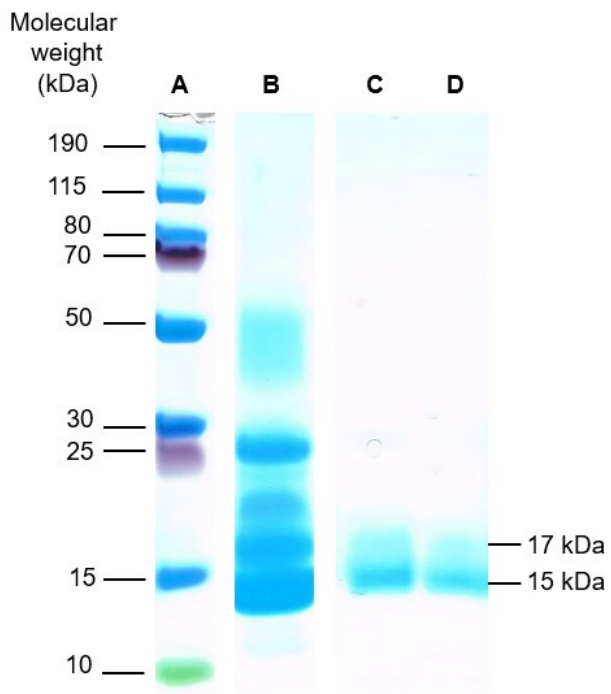

Fig 7. SDS-PAGE profile jacalin extracted by AOT reverse micelles. Lane A: protein markers; Lane B: crude extract of jackfruit seeds; Lane C: jacalin standard and Lane D: extracted jacalin

extract and jacalin standard. The SDS-PAGE profile is as shown in Fig. 7. The jackfruit seeds crude extract (Lane B) exhibited several protein bands from $10 \mathrm{kDa}$ to 50 $\mathrm{kDa}$. Meanwhile, the extracted jacalin (Lane D) shows two single bands at 15 and $17 \mathrm{kDa}$, similar to the protein bands observed in the samples of jacalin standard (Lane C). The similarity between the protein bands in the extracted jacalin and jacalin standard suggests that jacalin has been successfully extracted from the aqueous 
phase into the AOT reverse micelles. Furthermore, the SDS-PAGE profile for the extracted jacalin is in accordance with the SDS-PAGE results obtained by other researchers which observed molecular weights of jacalin in the range of 11 to $17 \mathrm{kDa}$ [9, 36-37].

\section{Comparison with Other Methods for Jacalin Extraction}

Jacalin has been previously isolated and purified by affinity chromatography on cross-linked guar gum with an initial step of ammonium sulfate precipitation. Although the use of ammonium sulfate as a precipitation agent for jacalin is well known; however, the standard protocol to be used in jacalin precipitation is still not available. Othman et al. [38] found a maximum yield of $0.425 \mathrm{~g} / \mathrm{g}$ dialyzed jacalin in the crude extract by fractional precipitation and recovered the jacalin in the ammonium sulfate fraction at $0-90 \%$ and $30-60 \%$ of saturation. However, excessive addition of ammonium sulfate interferes with the Lowry method used for protein determination, hence only caused a slight increase in jacalin precipitation. To avoid the use of ammonium sulfate in purification protocol, Roy et al. [39] attempted a one-step purification strategy of jacalin using the crosslinked alginate guar gum and obtained $1.67 \%$ of jacalin. Meanwhile, Zuraidah [20] demonstrated that 5\% of jacalin could be extracted using reverse micellar system. The current study, however, able to extract almost $83 \%$ of jacalin to the organic micellar phase, thus proved that the reverse micelles extraction method is better than other methods in terms of jacalin yield.

\section{- CONCLUSION}

Forward extraction of jacalin from the crude extract of jackfruit seed was successfully carried out using an anionic reverse micellar system made up of AOT in isooctane. A maximum forward extraction efficiency of $83 \%$ was achieved with aqueous phase $\mathrm{pH}$ of 5 , AOT concentration of $20 \mathrm{mM}, \mathrm{NaCl}$ concentration of $0.1 \mathrm{M}$, volume ratio organic to aqueous phase of $1: 1$ and $20 \mathrm{~min}$ contact time. The results obtained suggest the suitability of employing AOT reverse micelles to selectively transferred jacalin from the jackfruit seed crude extract.
The findings also provide valuable information which could be useful for subsequent step of backward extraction to recover jacalin from the reverse micellar phase with a new aqueous solution.

\section{- ACKNOWLEDGMENTS}

All authors gratefully acknowledge research funding and support from Universiti Malaysia Pahang through internal research grants (RDU170338), postgraduate research grant (PGRS170346) and scholarship (SLAI) awarded to Sharifah Fathiyah Sy Mohamad by Ministry of Higher Education (MOHE).

\section{- REFERENCES}

[1] Kabir, S., 1998, Jacalin: A jackfruit (Artocarpus heterophyllus) seed-derived lectin of versatile applications in immunobiological research, $J$. Immunol. Methods, 212 (2), 193-211.

[2] Chatterjee, B., Vaith, P., Chatterjee, S., Karduck, D., and Uhlenbruck, G., 1979, Comparative studies of new marker lectins for alkali-labile and alkali-stable carbohydrate chains in glycoproteins, Int. J. Biochem., 10 (4), 321-327.

[3] Lavanya, V., Kumar, B.A.,, Jamal, S., Khan, M.K.A., and Ahmed, N., 2017, Sub-micellar concentration of sodium dodecyl sulphate prevents thermal denaturation induced aggregation of plant lectin, jacalin, Protein J., 36 (1), 17-27.

[4] Ahmed, K.B.A., Reshma, E., Mariappan, M., and Anbazhagan, V., 2015, Spectroscopic investigation on the interaction of ruthenium complexes with tumor specific lectin, jacalin, Spectrochim. Acta, Part A, 137, 1292-1297.

[5] Obaid, G., Chambrier, I., Cook, M.J., and Russell, D.A., 2015, Cancer targeting with biomolecules: a comparative study of photodynamic therapy efficacy using antibody or lectin conjugated phthalocyaninePEG gold nanoparticles, Photochem. Photobiol. Sci., 14 (4), 737-47.

[6] Marangoni, V.S., Paino, I.M., and Zucolotto, V., 2013, Synthesis and characterization of jacalin-gold nanoparticles conjugates as specific markers for cancer cells, Colloids Surf., B, 112, 380-386. 
[7] Nascimento, K.S., Cunha, A.I., Nascimento, K.S., Cavada, B.S., Azevedo, A.M., and Aires-Barros, M.R., 2012, An overview of lectins purification strategies, $J$. Mol. Recognit., 25 (11), 527-541.

[8] Kumar, G.S., Appukuttan, P.S., and Basu, D., 1982, $\alpha$-D-galactose-specific lectin from jack fruit (Artocarpus integra) seed, J. Biosci., 4 (3), 257-261.

[9] Kabir, S., 1995, The isolation and characterisation of jacalin [Artocarpus heterophyllus (jackfruit) lectin] based on its charge properties, Int. J. Biochem. Cell Biol., 27 (2), 147-156.

[10] Polli, C.D., Ruas, L.P., Veronez, L.C., Geraldino, T.H., de Morais, F.R., Roque-Barreira, M.C., and Pereira-da-Silva, G., 2016, Jacalin-activated macrophages exhibit an antitumor phenotype, Biomed Res. Int., 2016, 2925657.

[11] Mazzola, P.G., Lopes, A.M., Hasmann, F.A., Jozala, A.F., Penna, T.C.V, Magalhaes, P.O., Rangel-Yagui, C.O., and Pessoa, A., 2008, Liquid-liquid extraction of biomolecules: An overview and update of the main techniques, J. Chem. Technol. Biotechnol., 83 (2), 143-157.

[12] Eskici, G., and Axelsen, P.H., 2016, The size of AOT reverse micelles, J. Phys. Chem. B, 120 (44), 1133711347.

[13] Chen, J., Chen, F., Wang, X., Zhao, X., and Ao, Q., 2012, The forward and backward transport processes in the AOT/hexane reversed micellar extraction of soybean protein, J. Food Sci. Technol., 51 (10), 28512856.

[14] Noh, K.H., and Imm, J.Y., 2005, One-step separation of lysozyme by reverse micelles formed by the cationic surfactant, cetyldimethylammonium bromide, Food Chem., 93 (1), 95-101.

[15] Pandey, R., Prabhu, A.A., and Dasu, V.V., 2018, Purification of recombinant human interferon gamma from fermentation broth using reverse micellar extraction: A process optimization study, Sep. Sci. Technol., 53 (3), 487-495.

[16] Prabhu, A.A., Chityala, S., Garg, Y., and Dasu, V.V., 2017, Reverse micellar extraction of papain with cationic detergent based system: An optimization approach, Prep. Biochem. Biotechnol., 47 (3), 234244.

[17] Nascimento, C.O., Costa, R.M.P.B., Araújo, R.M.S., Chaves, M.E.C., Coelho, L.C.B.B., Paiva, P.M.G., Teixeira, J.A., Correia, M.T.S., and Carneiro-daCunha, M.G., 2008, Optimized extraction of a lectin from Crataeva tapia bark using AOT in isooctane reversed micelles, Process Biochem., 43 (7), 779-782.

[18] He, S., Simpson, B.K., Ngadi, M.O., and Ma, Y., 2015, In vitro studies of the digestibility of lectin from black turtle bean (Phaseolus vulgaris), Food Chem., 173, 397-404.

[19] Tulyathan, V., Tananuwong, K., Songjinda, P., and Jaiboon, N., 2002, Some physicochemical properties of jackfruit (Artocarpus heterophyllus Lam) seed flour and starch, ScienceAsia, 28, 37-41.

[20] Mohd Ali, Z., 2015, Recovery Process of Jacalin from Crude Protein of Jackfruit Seed Powder: Optimization of Extraction and Cytotoxicity Study of Jacalin towards Human Cancer Cell, Dissertation, Universiti Malaysia Pahang.

[21] He, S., Shi, J., Walid, E., Zhang, H., Ma, Y., and Xue, S.J., 2015, Reverse micellar extraction of lectin from black turtle bean (Phaseolus vulgaris): Optimisation of extraction conditions by response surface methodology, Food Chem., 166, 93-100.

[22] Krishna, S.H., Srinivas, N.D., Raghavarao, K.S.M.S., and Karanth, N.G., 2002, Reverse micellar extraction for downstream processing of proteins/enzymes, Adv. Biochem. Eng. Biotechnol., 75, 119-183.

[23] Hemavathi, A.B., Hebbar, H.U., and Raghavarao, K.S.M.S., 2012, "Reverse Micellar Extraction of Bioactive Compounds for Food Products" in Enhancing Extraction Processes in the Food Industry, Eds., Libovka, N., Vorobiev, E., and Chemat, F., CRC Press, 399-436.

[24] Kinugasa, T., Kondo, A., Mouri, E., Ichikawa, S., Nakagawa, S., Nishii, Y., Watanabe, K., and Takeuchi, H., 2003, Effects of ion species in aqueous phase on protein extraction into reversed micellar solution, Sep. Purif. Technol., 31 (3), 251-259.

[25] Nandini, K.E., and Rastogi, N.K., 2009, Reverse 
micellar extraction for downstream processing of lipase: Effect of various parameters on extraction, Process Biochem., 44 (10), 1172-1178.

[26] Bu, G., Liu, H., Chen, F., Liu, K., Yang, Y., and Gao, Y., 2012, Effects of different factors on the forward extraction of soy protein in reverse micelle systems, Afr. J. Biotechnol., 11 (28), 7247-7257.

[27] Moreira, R.A., Castelo-Branco, C.C., Monteiro, A.C.O., Tavares, R.O., and Beltramini, L.M., 1998, Isolation and partial characterization of a lectin from Artocarpus incisa L. seeds, Phytochemistry, 47 (7), 1183-1188.

[28] Chen, Y.L., Su, C.K., and Chiang, B.H., 2006, Optimization of reversed micellar extraction of chitosanases produced by Bacillus cereus, Process Biochem., 41 (4), 752-758.

[29] Pawar, S.S., Regupathi, I., and Prasanna, B.D., 2017, Reverse micellar partitioning of Bovine Serum Albumin with novel system, Resour.-Effic. Technol., 3 (4), 491-494.

[30] He, Z., Tan, J.S., Abbasiliasi, S., Lai, O.M., Tam, Y.J., Halim, M., and Ariff, A.B., 2015, Primary recovery of miraculin from miracle fruit, Synsepalum dulcificum by AOT reverse micellar system, LWT Food Sci. Technol., 64 (2), 1243-1250.

[31] Gangadharappa, B.S., Dammalli, M., Rajashekarappa, S., Pandurangappa, K.M.T., and Siddaiah, G.B., 2017, Reverse micelles as a bioseparation tool for enzymes, J. Proteins Proteomics, 8 (2), 105-120.

[32] Pires, M.J., Aires-Barros, M.R., and Cabral, J.M.S., 1996, Liquid-liquid extraction of proteins with reversed micelles, Biotechnol. Prog., 12 (3), 290-301.
[33] Nandini, K.E., and Rastogi, N.K., 2010, Single step purification of lactoperoxidase from whey involving reverse micelles-assisted extraction and its comparison with reverse micellar extraction, Biotechnol. Prog., 26 (3), 763-771.

[34] Gaikaiwari, R.P., Wagh, S.A., and Kulkarni, B.D., 2012, Extraction and purification of tannase by reverse micelle system, Sep. Purif. Technol., 89, 288296.

[35] Pawar, S.S., Iyyaswami, R., and Belur, P.D., 2017, Reverse micellar extraction of lactoferrin from its synthetic solution using CTAB/n-heptanol system, J. Food Sci. Technol., 54 (11), 3630-3639.

[36] Young, N.M., Johnston, R.A.Z., and Watson, D.C., 1991, The amino acid sequences of jacalin and the Maclura pomifera agglutinin, FEBS Lett., 282 (2), 382-384.

[37] Pratap, J.V., Jeyaprakash, A.A., Rani, P.G., Sekar, K., Surolia, A., and Vijayan, M., 2002, Crystal structures of artocarpin, a Moraceae lectin with mannose specificity, and its complex with methylalpha-D-mannose: Implications to the generation of carbohydrate specificity, J. Mol. Biol., 317 (2), 237-247.

[38] Othman, M.R., Min, L.M., and Fernando, W., 2006, Isolation and purification of jacalin from Artocarpus heterophyllus Lam, IIUM Eng. J., 7 (1), 71-81.

[39] Roy, I., Sardar, M., and Gupta, M.N., 2005, Crosslinked alginate-guar gum beads as fluidized bed affinity media for purification of jacalin, Biochem. Eng. J., 23 (3), 193-198. 